\title{
Fabrication of Dexamethasone-Silver Nanoparticles Entrapped Dendrimer Collagen Matrix Nanoparticles for Dental Applications
}

\author{
Ramyaa Shri K ${ }^{1}$, Subitha P, Srinivasan Narasimhan ${ }^{1}$, Ramachandran Murugesan ${ }^{1}$, Shoba Narayan 1,*(D) \\ 1 Faculty of Allied Health Sciences, Chettinad Hospital and Research Institute, Chettinad Academy of Research and \\ Education, Kelambakkam, Tamilnadu, 603103, India \\ * Correspondence: shobulu@gmail.com;
}

Scopus Author ID 10142117400

Received: 28.02.2021; Revised: 25.03.2021; Accepted: 28.03.2021; Published: 7.04.2021

\begin{abstract}
A bioengineered tooth is a well-studied subject. However, it is a challenge when seamless integration of various functionalities is required. In the case of teeth, integrating stem cell differentiating agents, regenerating the dentin tissue, and arresting the biofilm formation are three aspects that call for attention. Dental pulp stem cell differentiation to odontoblasts can be facilitated by dexamethasone (Dex). The ideal scaffold for regeneration applications - collagen (Col), has several advantages but also has no inherent rigidity. Silver nanoparticles (AgNps) are found to be an ideal material for preventing biofilm formation, with challenges arising from their stability and cytotoxicity. The route was chosen based on the successful demonstration of various platforms is the PAMAM (Den) dendrimers. The platform encompassing all the ingredients - AgNp@Den@Dex@Col had a $\lambda_{\max }$ at 622 nm. FTIR studies revealed the presence of all components, and scaffold degradation temperature improved. A linked morphology was observed under TEM, and the zone of inhibition (MIC) was $3.5 \mathrm{~mm}$, indicating good antibacterial activity. There was also a $60 \%$ reduction in biofilm formation against Staphylococcus aureus and $40 \%$ against Klebsiella pneumoniae by the fabricated nanocomposite AgNp@Den@Dex@Col. In essence, this work reports a platform where three functions of stem cell differentiation, regeneration, and biofilm formation are integrated.
\end{abstract}

Keywords: AgNp; PAMAM dendrimers; collagen; biofilm; dexamethasone.

(C) 2021 by the authors. This article is an open-access article distributed under the terms and conditions of the Creative Commons Attribution (CC BY) license (https://creativecommons.org/licenses/by/4.0/).

\section{Introduction}

Dental plaque and its tie-up to oral health and diseases have been studied for decades. The dental biofilm, which contains more than 700 bacterial species, causes diseases such as dental caries and periodontal diseases in the teeth and their supporting tissues. Streptococcus mutans and Staphylococcus aureus are linked to infections like dental caries and infections to other medical implants. Due to acid production, microbial biofilm in the teeth can lead to demineralization and damage to the hard tissues, which have a different regenerative capacity that ultimately leads to loss of teeth. Researchers worldwide have attempted to improve dental materials' clinical performance, yet a major issue lies at the multifunctional level: a) biofilm degradation, b) re-mineralization, and c) tooth regeneration. Nowadays, innovative biomaterials have been developed to create highly cellularized bioengineered teeth to prevent cavities, and treatment is aimed for larger appeal [1]. 
The ideal source of pulp stem cells of dental origin in four different dental tissues: a) apical papilla, b) human exfoliated deciduous teeth, c) periodontal ligament, and d) dental follicle tissue. The natural function of dental pulp stem cells is to transform into odontoblasts that form dentin, neural cells, and adipocytes. The advantages associated with dental pulp stem cells are: a) easy access to collection sites and low morbidity, b) highly efficient extraction of stem cells from pulp tissue, c) extensive differentiation, and d) interactivity with biomaterials [2]. The mesenchymal stem cells from the dental pulp of exfoliated deciduous teeth, abbreviated as SHED can differentiate in vitro to neuro-like cells and odontoblasts. Their capacity to produce dentin and form bones is higher than the dental pulp stem cells $[3,4]$. However, dental pulp stem cells continue to be an easy and direct source of dental stem cells for tissue engineering and regeneration purpose. An examination of human dental pulp cells' cell differentiation potential seeded on mechanically and chemically treated dentin surfaces indicated that they developed into an odontoblast-like morphology [5,6]. The differentiated odontoblast cells secrete reparative dentin. For bioengineering of the tooth, the pulp cell differentiation to odontoblasts needed to be triggered in vitro. Researchers identified dexamethasone (Dex), a synthetic glucocorticoid, as having the potential to induce odontogenic differentiation [7]. Dexamethasone stimulated alkaline phosphatase activity and induced expression of transcript encoding dentin sialophosphoprotein, a major odontoblastic marker. How dexamethasone was released to the medium containing pulp cells was found to influence pulp cells' odontogenic differentiation [8]. Dexamethasone delivery systems ranging from systemic injection to coating and loading within biodegradable polymeric carriers have been developed over time. Biphasic calcium phosphate nanoparticle -collagen (Col) scaffolds were recently demonstrated to promote dexamethasone's controlled release. In relationship to ex vivo culturing of stromal cells, Oliveira et al. (2010) [9] demonstrated that carboxymethyl chitosanPAMAM dendrimers (Den) were able to provide for a controlled release of dexamethasone.

The next step in developing a bio tooth is to harvest the stem cells and incorporate them within a scaffold for implantation at the site of tooth loss [10]. Cells are plated on the scaffolds either through in vitro method or cell homing. The cell homing method is an in vivo method where endogenous stem cells from adjacent host sites are mobilized and inhabited to the scaffold matrix, thereby avoiding the isolation and manipulation of cells in the laboratory. As tooth has both hard and soft tissues, multiple approaches have to be combined with regenerating teeth. One approach is to create a three-dimensional scaffold that is rich in growth factors, seeding the cells in a manner in which tissue of desired size and architecture can be obtained. Subsequent implantation in sites where sufficient blood supply, oxygen, and nutrition is available would lead to the tissue's maturation [11]. The maturation is also achieved through in vitro techniques. The current challenge, however, is the seamless integration of various steps. In another approach, the three-dimensional scaffold can be replaced with a soft scaffold matrix, and this is useful for tissue generation within the pulp cavity.

To date, both natural and synthetic biomaterials have been employed for constructing scaffolds. This includes proteins like collagen [12, 13], fibrin, silk; polysaccharides like chitosan, alginate, hyaluronic acid, etc.; synthetic polymers like polylactic acid polycaprolactone. Along with these biomaterials, compounds like hydroxyapatite, amorphous calcium phosphate, tricalcium phosphate, and compositions of silicate and phosphate glasses are also used to form porous scaffolds [14].

Same biomaterials can serve both as hard and soft scaffolds. By definition, a soft scaffold can be injected as they demonstrate a sol-gel conversion. These compounds are also 
called hydrogels, and classic examples of those employed in tooth engineering are collagen, fibrin, PEG, silk, etc. The hydrogel formation techniques are thermal gelation, ionic interaction, physical cross-linking, polymerization, and chemical cross-linking [15].

Collagen is one of the most popular extracellular matrix (ECM) molecules and is used in native form or as denatured gelatin. Abundance, ubiquity, and biocompatibility make collagen type I the most popular collagenous material for scaffolds. Collagen is naturally extracted, most preferably from skin, bones, rat-tail tendon, jellyfish skeletons, and fish scales, and can be prepared both as swollen hydrogel or cross-linked fibers [16]. Collagen is isolated from the source at around $4{ }^{\circ} \mathrm{C}$ and in acids such as acetic acid. This removes the noncollagenous proteins, lipids and performs decalcification when isolated from bones. The extracted collagen is stored by way of lyophilization. One of the significant challenges is that the acid-soluble collagen loses its intra/inters molecular bonds and swells. Further, at temperatures above $40{ }^{\circ} \mathrm{C}$, a helix-to-coil transition also occurs, destroying the natural crosslinks and possible conversion to gelatin [16]. This results in poor tensile strength when compared to native collagen [18].

Chemical cross-linking has been in vogue for a long, including in the conversion of skin to leather. This includes a) covalent amine/imine linkage using glutaraldehyde, isocyanate etc., b) linking the carboxyl group of collagen through 1-Ethyl-3-(3dimethylaminopropyl)carbodiimide (EDC), c) H-bonding through polyphenols, and d) metal protein interactions through metal ions like chromium [19].

More benign materials have now replaced the most popular glutaraldehyde and metal complex cross-linking. Several plant-based crosslinkers have been identified for cross-linking collagen. This includes plumbagin, curcumin, shikimic acid etc. [20]. However, in many instances, the natural product-based cross-linking alone is not able to satisfy the mechanical requirements for a scaffold. Nanoparticle-mediated cross-linking of collagen has gained attention in recent times. This includes those of gold, silver nanoparticles, zinc oxide nanoparticles, etc. [21-24].

Combining nano-biomaterials that can resemble ECM structures provides an opportunity for engineering teeth. Amongst the various materials, one of the branch structured nanomaterial that has caught attention is the dendrimer. Dendrimers are branched, symmetrical, and monodisperse core-shell nanostructures, which can be synthesized in a branched manner with diverse surface functionalities. Among various dendrimers such as polyamidoamine (PAMAM), poly (alkyl aryl ether), poly-L-lysine, etc., the PAMAM dendrimers are the most popular that could mimic the natural mineralization process of dental hard tissues. The dendrimers are iteratively grown from a central core. Every iteration or subsequent step is referred to as a generation. Increasing generations or molecular weight increases the diameter doubles the reactive sites. Each generation is also dual the molecular weight of the earlier generation. They are three-dimensional and have a structure that resembles biological macromolecules, leading to the dendrimers being referred to as artificial proteins [25]. For instance, an ammonia core Generation 3 to 5 PAMAM dendrimer resembles insulin, cytochrome, and hemoglobin, respectively.

Dendrimer-based dental composites have attracted attention because of the higher cross-link density, decreased water sorption and solubility, improved mechanical properties, and higher resin melting temperature [26]. For in situ re-mineralization of human tooth enamel, Alendronate conjugated carboxyl-terminated PAMAM has been reported to be a promising 
restorative biomaterial [27]. Phenylalanine modified G3 PAMAM dendrimers have been reported to increase the delivery efficiency of antibacterial [28].

The advancement of nanomaterials in dental science has been phenomenal. Sharan et al. (2017) [29], in a review article, have traced the growth path in dentistry's various specialty areas. Oral administration of antibiotics causes systemic side effects. The access of antibiotics to deeper pockets areas in teeth is also limited. Nano drug delivery systems that increase the retention time and penetrate into inaccessible areas such as periodontal pocket is considered advantageous for biofilm management [30].

Metal nanoparticles, more so those such as silver nanoparticles, are known to have antimicrobial properties [31] by way of their ability to generate radical oxygen species. The disruption of bacteria DNA leads to loss of ability to reproduce [32]. Silver has been a part of restorative materials, such as silver nitrate, silver bromide, etc. [33,34]. However, for the same quantity of silver nanoparticles and silver nitrate solutions, nanoparticles had a closer coating arrangement. While the antibacterial and anti-biofilm properties were the same, the nanoparticle-based coating did not discolor the teeth and also maintained structural integrity over a higher time than silver nitrate. As of date, research indicates that silver nanoparticles can be incorporated into composite resins, dental primer, and dental adhesives. The selfdiffusion coefficient of silver nanoparticles in a biofilm decreased exponentially with the square of the nanoparticle's radius [35].

It has been reported that the success of silver nanoparticles in biomedical applications is limited by the stability of bare nanoparticles and the high level of cytotoxicity $[36,37]$. Nextgeneration silver nanoparticles such as polysaccharide capped silver nanoparticles have been reported to have better properties. While the nanoparticle would provide for appropriate structure, viz., rigid, hollow, or porous, the nanoparticle's functionalization would address how the nanoparticles would be assembled and interact with the biofilm [38]. However, functionalization could also passivate the nanoparticles, thus making them not available for antimicrobial properties.

Dendrimers are well suited to host nanoparticles as they have a uniform structure and composition. Encapsulation of nanoparticles with dendrimers prevents their aggregation and remains confined by steric effects and thus available for catalytic reactions [39].

Several authors have reported the preparation of silver-dendrimer nanocomposites, with silver nanoparticle size reducing with an increase in dendrimer generation. Based on the literature's identified opportunities, this work focuses on providing an appropriate platform where multiple steps involved in developing a bioengineered tooth could be seamlessly integrated. Accordingly, the objective of the investigation is to develop PAMAM dendrimer into a platform where a) dental pulp stem cells differentiation to odontoblasts could be facilitated through controlled release of dexamethasone, b) collagen scaffold for regeneration of dentin tissue could be stabilized, and c) silver nanoparticles that can arrest biofilm formation can be encapsulated.

\section{Materials and Methods}

\subsection{Materials.}

Sigma Aldrich and/or Himedia was the source for the chemicals used. . Bacterial strains: Staphylococcus aureus and Klebsiella pneumoniae were generous gifts from the 
Department of Microbiology, Chettinad Hospital, and Research Institute. Reagents/chemicals utilized in this study were of analytical grade and used as received without further purifying.

\subsubsection{Synthesis of Silver Nanoparticle (AgNp).}

The silver nanoparticle was synthesized by the citrate reduction method [40]. Silver nitrate and trisodium citrate were used as starting materials for the preparation of $\mathrm{AgNp}$. In 500 $\mathrm{mL}$ of a round bottom flask, $8 \mathrm{mg}$ of silver nitrate was dissolved with $47.5 \mathrm{~mL}$ of Milli Q water while stirring and heating to boiling continuously using a magnetic stirrer. Change in the color of the solution from milky whitish to pure white was noted. After bubble formation, $2.5 \mathrm{~mL}$ of trisodium citrate was added rapidly using a syringe to the round bottom flask. After a few min, vigorous stirring was continued for $15 \mathrm{~min}$. The colloid color was changed to pale yellow, an indication of nanoparticle formation using citrate as a capping agent.

\subsection{Fabrication of dendrimer stabilized drug-loaded nanoparticles} (AgNP@Den@Dex@Col).

Dendrimer (PAMAM- Polyamidoamine ) stabilized silver nanoparticles were prepared based on the modified procedure as described earlier [41]. $100 \mu \mathrm{L}$ of the solution, which contains $5 \mathrm{mg}$ of a dendrimer, was stirred for $1 \mathrm{~h}$. Now at this stage, to functionalize silver nanoparticles with dendrimer, $100 \mu \mathrm{L}$ containing $50 \mu \mathrm{g}$ of silver nanoparticles (analyzed by ICP OES analysis) was added and stirred for $2 \mathrm{~h}$. The functionalization of dendrimer to silver nanoparticles was observed through a color change. Incorporation of Dex to AgNp@Den was done by an earlier method [42]. $1 \mathrm{mg}$ of dexamethasone was weighed and dissolved in $70 \%$ ethanol. $100 \mu \mathrm{L}$ containing $100 \mu \mathrm{g}$ of dexamethasone was added dropwise to the continuously stirred AgNp@Den solution and was stirred for $2 \mathrm{~h}$. The final concentration of dexamethasone was $255 \mu \mathrm{M}$. To activate the carboxylic group of collagen, $15 \mu \mathrm{L}$ of collagen was added to 1 $\mathrm{mL}$ of EDC solution containing $1 \mathrm{mg}$ of EDC, it was dissolved using $2 \mathrm{~mL}$ of $1 \%$ acetic acid. Followed by stirring was continued for $2 \mathrm{~h}$ to activate the carboxylic group of collagen and stored under -20 ${ }^{\circ} \mathrm{C}$ for further uses. To cross-link the collagen to AgNp@Den@Dex, $100 \mu \mathrm{L}$, which contains $6 \mu \mathrm{g}$ of activated collagen, was added to AgNp@Den@Dex. The solution was kept in a vial shaker for $3 \mathrm{~h}$. so that the amine group of dendrimer can bind with the carboxylic group of collagen. The color change can see the binding of collagen to the PAMAM of the solution. There was a bluish-black color appeared after adding collagen. Then the bluish-black color was disappeared. To remove unbound EDC, the solution was dialyzed against deionized water. This procedure was carried out by modifying earlier methods [43].

\subsection{Physiochemical characterizationofAgNP@Den@Dex@Col.}

To understand the binding and functionalization of AgNP, the prepared NP of all groups were characterized by UV-Vis spectrophotometry to understand the shift in the peak of silver nanoparticles. Dynamic Light Scattering (DLS) technique was carried out to understand the size distribution; Zeta potential measurements to understand stability and to know the charge that of the molecules that are bound on the nanoparticle surface, Thermogravimetric analysis to understand the thermal behavior of collagen; Transmission Electron Microscope (TEM) was carried out to understand the nanomaterial formation upon interaction with collagen; Fourier Transform Infrared Spectroscopy (FTIR) was used to determine the adsorption/entrapment of drugs in nanomaterial. 


\subsection{Bacterial growth inhibition (MIC assay).}

To know the growth inhibition percentage [44] of silver nanoparticles, dendrimer, silver nanoparticles functionalized with dendrimer, silver nanoparticles functionalized with dendrimer entrapped with dexamethasone, silver nanoparticles functionalized with dendrimer entrapped with dexamethasone that is cross-linked with collagen $50 \mu \mathrm{L}$ of the samples were added to test tubes containing Staphylococcus aureus or Klebsiella pneumoniae. Briefly, respective cultures were grown for $12 \mathrm{~h}$ in a test tube containing nutrient broth. Then, $1.9 \mathrm{~mL}$ of nutrient broth was taken in 12 tubes, 6 for Staphylococcus aureus and 6 for Klebsiella pneumoniae. $10 \mu \mathrm{L}$ of bacterial culture was added to tubes except for control tubes. The tubes were placed in a shaker at $37^{\circ} \mathrm{C}$ for $10 \mathrm{~h}$. At the end of $10 \mathrm{~h}$, optical density at $600 \mathrm{~nm}$ was recorded. The percentages of inhibition of bacteria by the nanomaterial were calculated based on the formula below:

$$
\text { Optical Density }(\%)=100 \times\left(\frac{\text { Control OD }}{\text { Test OD }}\right)
$$

\subsection{Evaluation of antibacterial activity.}

To understand the minimum inhibitory effect of synthesized and fabricated nanomaterial [45,46], AgNP@Den@Dex@Col was carried out in different concentrations ranging from 5 to $35 \mu \mathrm{g} / \mathrm{mL}$ in well and incubated for 24 hours. To understand the effect of silver nanoparticles alone, dendrimer alone, silver nanoparticles functionalized with dendrimer and entrapped with dexamethasone and cross-linked dendrimers were studied for the inhibitory effect of these against gram-positive bacteria (Staphylococcus aureus) and gram-negative bacteria (Klebsiella pneumonia). The antibacterial activity was evaluated on nutrient agar with two bacterial strains by the well diffusion method. The aseptic condition was used to spread bacterial growth over the agar surface. $50 \mu \mathrm{L}$ of the nanoparticles with different concentrations of AgNP were loaded into the well and incubated at $37{ }^{\circ} \mathrm{C}$ for $24 \mathrm{~h}$. After incubating for 24 hours, material diffuses in the agar medium, inhibiting the growth through the inhibition zone.

\subsection{Biofilm formation assay.}

Biofilm formation and prevention of biofilm [47] were done for two organisms (Staphylococcus aureus and Klebsiella pneumoniae). Bacterial suspension of $100 \mu \mathrm{L}$ was inoculated in nutrient broth and incubated at $37^{\circ} \mathrm{C}$ for $24 \mathrm{~h}$. To each well (sterile flat bottomed 96 well polystyrene microtiter plates), inoculated bacterial suspension (100 $\mu \mathrm{L}$ ( 6000$) \mathrm{cfu}$ ) was added and incubated at $37{ }^{\circ} \mathrm{C}$ for $24 \mathrm{~h}$, to allow bacterial cell adhesion and biofilm formation on surfaces. The supernatant was discarded, and the non-attached cells were removed after $24 \mathrm{~h}$ using $100 \mu \mathrm{L}$ of $0.9 \%$ (W/V) sodium chloride. Biofilms were washed two times with Milli Q water, and existing biofilms were served with $50 \mu \mathrm{L}$ of nutrient broth containing with or without $50 \mu \mathrm{L}$ of nanomaterial (A) Control, B) AgNp, C) AgNp@ Den, D) AgNp@Den@Dex, E) AgNp@Den@Dex@Den@Col, F) Den, G) Col) was incubated at 37 ${ }^{\circ} \mathrm{C}$ for $24 \mathrm{~h}$. Biofilm incubated only with the nutrient broth was used as a control. After the incubation, the supernatant containing non-attached cells was washed using $100 \mu \mathrm{L}$ of $0.9 \%$ $(\mathrm{W} / \mathrm{V}) \mathrm{NaCl}$. Biofilm attached in the wells were fixed for $20 \mathrm{~min}$, and the plates were air-dried at room temperature for $20 \mathrm{~min}$. 


\subsection{Biofilm staining assay.}

The staining method was followed by the previous procedure steps. $1 \%$ crystal violet $(100 \mu \mathrm{L})$ was used to stain Staphylococcus aureus biofilm with and without nanoparticles (AgNP@Den@Dex@Col) and incubated for 20 min at RT. After the incubation, the stain was washed, and the plates were rinsed thoroughly three times with distilled water, followed by solubilization using $150 \mu \mathrm{L}$ of $1 \%$ glacial acetic acid. Biofilm formation (color formation) was quantified by measuring absorbance at $590 \mathrm{~nm}$. The same procedure was carried out for Klebsiella pneumoniae, also using safranin stain, the biofilm was measured at $550 \mathrm{~nm}$.

\subsection{Scanning electron microscopic (SEM) analysis.}

HR SEM analysis was carried out to understand the cell morphology changes with or without AgNP@Den@Dex@Col. Biofilm was formed on coverslips, and cells were fixed using $1 \mathrm{~mL}$ of $2.5 \%$ glutaraldehyde and kept at $4{ }^{\circ} \mathrm{C}$ for $24 \mathrm{~h} .1 \mathrm{~mL}$ of $1 \mathrm{X}$ PBS was used for washing coverslips after incubation, and the coverslips were washed three times. By increasing the percentage of alcohol, cells were dried out for $10 \mathrm{~min}$. Coverslips were cut and mounted onto aluminum stubs with carbon tape for the HR SEM analysis [48].

\subsection{Statistical analysis.}

This was done with the use of the student's t-test, and $\mathrm{P}<0.05$ is considered significant statistically.

\section{Results and Discussion}

\subsection{Preparation and characterization of silver nanoparticles (AgNps).}

Silver nanoparticles were synthesized using trisodium citrate as a reducing agent. The formation of nanoparticles of silver can be confirmed by yellow color formation, as shown in Figure 1. On the right-hand side, the color formation upon fabrication is presented. $100 \mu \mathrm{g}(200$ $\mu \mathrm{L}$ ) of silver, when added to $1800 \mu \mathrm{L}$ of water, shows a dispersed silver nanoparticle as indicated by yellow color (A). The functionalization of dendrimer to silver nanoparticles can be seen as the change of the solution's color (B). To the functionalized silver nanoparticles, dexamethasone is added to entrap in the dendrimer's cavities. The entrapment can be visualized by the change in color of the solution (C). The solution was then cross-linked to collagen by way of EDC chemistry and then dialyzed. The change in color formation after cross-linking can be seen in the picture below (D). Silver nanoparticles were synthesized by varying the concentration of citric acid added. After fine-tuning silver nanoparticles' synthesis by measuring the hydrodynamic diameter $(\mathrm{DH})$, excess citric acid was removed. Silver nanoparticles were added to the dendrimer and stirred well. Next to that, dexamethasone was added so that the drug can fill the cavities. At this step, the solution was not dialyzed. Collagen was mixed with EDC so as to activate the carboxylic group and bind to the amine group of the dendrimer. After this, EDC and unbound dexamethasone was removed by dialysis. The flow of synthesis is presented in Figure 1.

To understand any changes in the $\lambda$ max by binding PAMAM to silver nanoparticles, the UV-Vis spectrum was recorded for the range from $300 \mathrm{~nm}-700 \mathrm{~nm}$. The $\lambda$ max of unpurified silver nanoparticles was found to be $429 \mathrm{~nm}$ (A). The $\lambda$ max of purified silver nanoparticles as seen from B is $415 \mathrm{~nm}$. Figure. 2 provides information on the UV-Vis spectra 
of AgNP@Den $\lambda \max$ at 416 nm, AgNP@Den@Dex $\lambda \max$ at 416 nm, and AgNP@Den@Dex@Col $\lambda$ max at 622 nm.

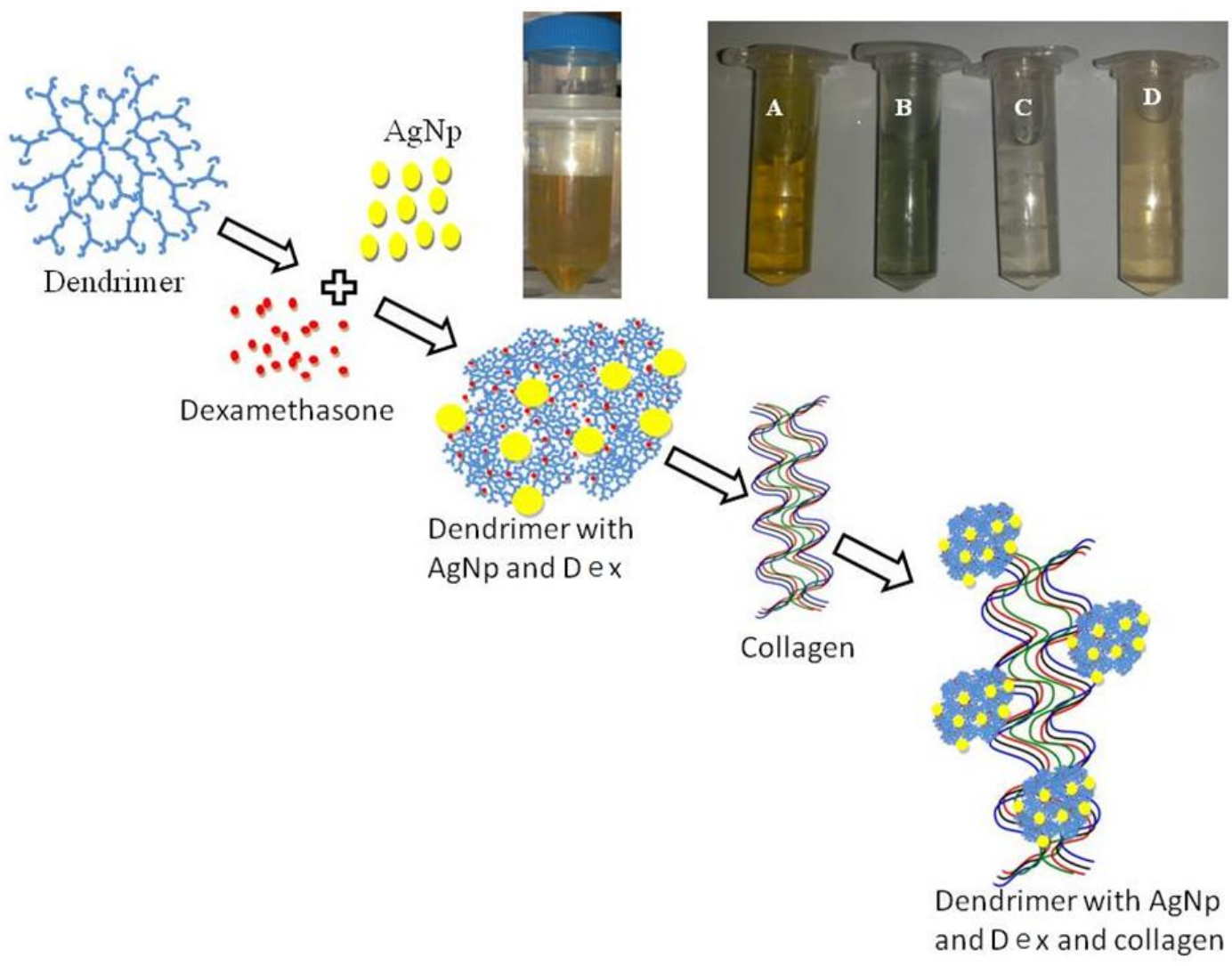

Figure 1. Steps involved in the synthesis and fabrication of nanocomposites; (A) AgNp; (B) AgNp@Den; (C) AgNp@Den@Dex; (D) AgNp@Dex@Den@Col.

Silver nanoparticles are used as antimicrobials, and their use in dentistry has gained significance use as a promising platform for their use against tumors, inflammation, and a wide range of microbes [49]. However, though silver has gained significance, bare silver nanoparticles are toxic to the system, and due to this, it is difficult to extrapolate the in vitro activity to in vivo activity [50-52]. Thus, silver nanoparticles are functionalized or incorporated in carrier systems like chitosan, gelatin, dendrimer, protein, etc., to reduce toxicity and increase efficacy. The release of drug or silver nanoparticles from the matrix has been shown to improve silver nanoparticles' activity [53]. Based on the above advantages of silver nanoparticles, especially in the dental field, we used silver nanoparticles for antibacterial activity in the current study.

Figure 2 provides detailed information on the surface plasmon resonance band of silver nanoparticles, purified silver nanoparticles, and fabricated silver nanoparticles. The shift in the absorbance to a shorter wavelength could be due to a decrease in hydrodynamic diameter which could be due to the removal of excess citric acid from the solution [54]. UV-Vis spectra of AgNp@Den compared to AgNp show an absorbance maximum at $416 \mathrm{~nm}$, indicating the functionalization of dendrimer on silver nanoparticles [55,56]. An interesting observation in the study is that when dexamethasone was added to the AgNp@Den and analyzed for any change in the spectra, it can be seen that the $\lambda$ max remained the same at $416 \mathrm{~nm}$, a clear indication that dexamethasone is entrapped in the dendrimer and not bound to silver 
nanoparticles.AgNP@Den@Dex, when cross-linked with collagen, showed a shift in the $\lambda$ max to a longer wavelength at $622 \mathrm{~nm}$. A large shift in the $\lambda$ max is a clear indication of the formation of mesh-like structures wherein nanoparticles are arranged in an orderly fashion along with the collagen matrix.
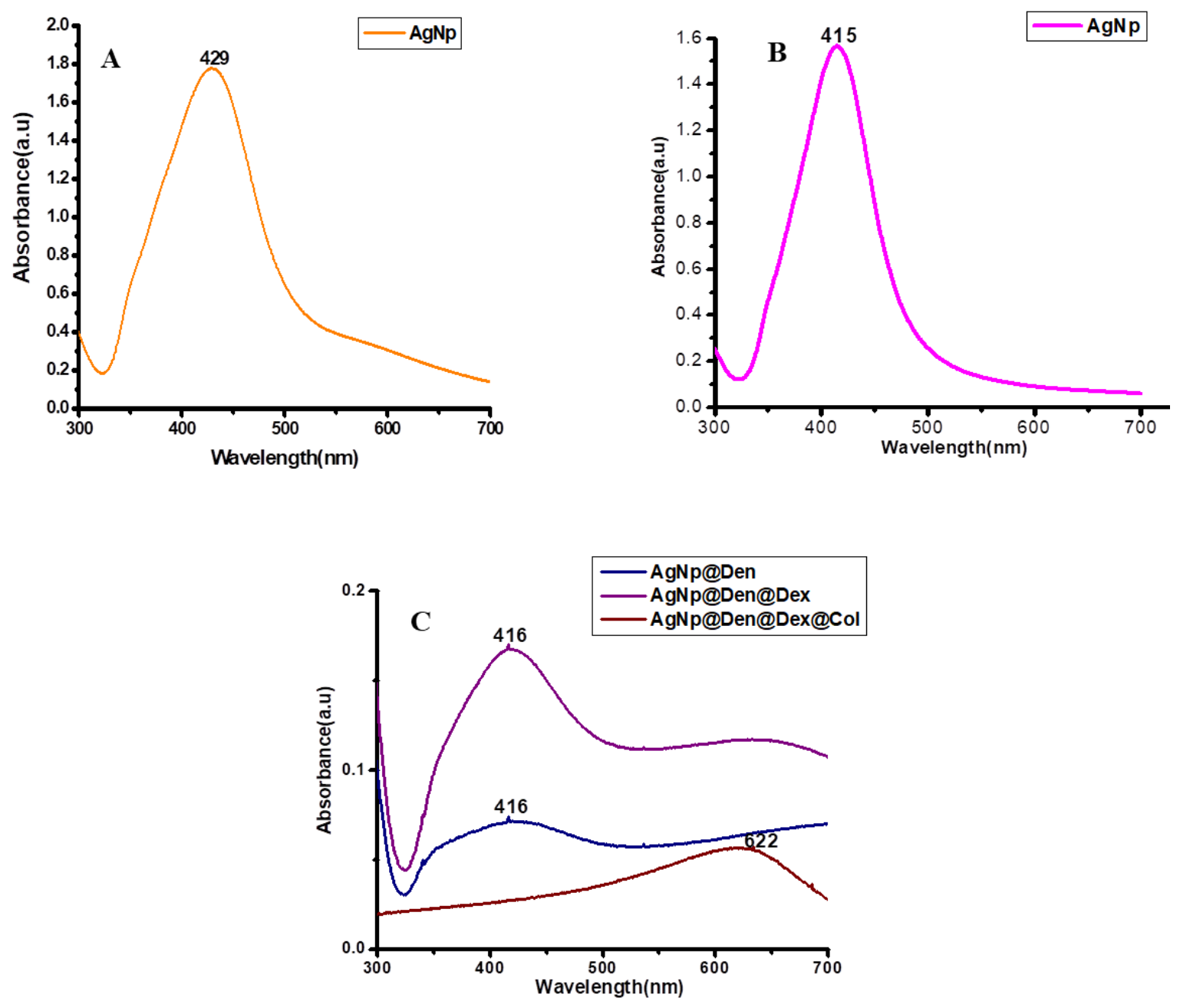

Figure. 2. UV-Absorbance spectra for (A) AgNp before centrifuge; (B) AgNp after centrifuge; (C) AgNp@Den,AgNP@Den@Dex, and AgNp@Den@Dex@Col.

Dendrimer, especially PAMAM dendrimer, is gaining tremendous importance due to much functionality and its ability to be functional at lower generations and as a nanoparticle carrier at higher generations [57]. It is also interesting to note that dendrimers like PAMAM dendrimers have the ability to prevent the formation of bacteria [58]. Due to the multifunctional capability of PAMAM dendrimers, in this study, the PAMAM dendrimer of generation 3 was chosen, and this was functionalized on silver nanoparticles such that dendrimer and silver nanoparticles are bound in a web-like fashion [59]. This study differs from the earlier study with the incorporation of dexamethasone inside the cavities of the dendrimer. Earlier reports have indicated that dexamethasone included in the culture medium can stimulate pulp origin's dental cells into odontoblast [60]. Dexamethasone is a glucocorticoid that is recommended to relieve pain [61]. It is reported that dexamethasone can stimulate the stem cells of dental pulp origin even at very minute concentration. In this study, the color change in the appearance of nanocomposites entrapment, functionalization, and cross-linking with collagen can be confirmed from Figure 1. 
A major portion of the dental component is collagen, and it provides an important role to part of the extracellular matrix. However, collagen as such, when incorporated or bound to nanomaterials, has lesser mechanical properties [62]. In this study, to develop a biomimetic approach, silver nanoparticles embedded along with dendrimer carrying dexamethasone was cross-linked with collagen to provide a matrix-like structure to the composites developed. This study chose EDC as a crosslinker as we wanted a liquid formulation and not hydrogels. Other types of crosslinkers like glutaraldehyde can cross-link dendrimer, but more instances form a hydrogel. Glutaraldehyde is toxic, whereas EDC is a zero-length crosslinker i.e., it can be successfully removed either by dialysis or centrifugation from the system. Reports have also suggested that cross-linking PAMAM with collagen is a better way for safe biomedical applications [63,64]. As the dental matrix is predominately made up of collagen Type I [65], we activated the carboxylic group amino acids present in collagen and was allowed to form a covalent amide bond with the amine group of the dendrimer. In the process, collagen fibrils [66-68] can form cross-linked collagen and bind with the dendrimer's free amine group.

\subsection{Characterization of AgNp@Den@Dex@Col: Hydrodynamic diameter, Zeta potential,} TEM analysis, FTIR- spectra, and TGA analysis.

Nanoparticles were synthesized and fabricated using silver nanoparticles before (A1, $\mathrm{B} 1, \mathrm{C} 1$, and D1) and after purification. The hydrodynamic diameter (d. $\mathrm{nm}$ ) of nanoparticles and composites was found to be $53 \mathrm{~d}$. nm - AgNp (A); $423 \mathrm{~d}$. nm - AgNp@Den (B); $362 \mathrm{~d}$. nm-AgNp@Den@Dex (C) and 324 d.nm - AgNp@Den@Dex@Col (D). As the diameter was largely due to the presence of excess citric acid, in the current study, the purified silver nanoparticles were used. The hydrodynamic diameter of purified nanoparticles and fabricated using those particles was found to be 35 d.nm - AgNp (A); 320 d.nm - AgNp@Den (B); 315 d.nm - AgNp@Den@Dex (C) and 166 d.nm - AgNp@Den@Dex@Col (D). The size distribution of these particles is present in Figure 3.

From the Figure. 3 it can be seen that silver nanoparticles diameter before purification was $53 \mathrm{~d}$. $\mathrm{nm}$ as compared to $35 \mathrm{~d}$. $\mathrm{nm}$ after purification, which is in good correlation with the study. The hydrodynamic diameter of fabricated nanoparticles of purified and unpurified silver nanoparticles gave different results. To get a specific binding of the nanoparticles, the particles were purified and fabricated as the functionalization and entrapment were carried out, the $\mathrm{d}$. $\mathrm{nm}$ increased, but after collagen, the $\mathrm{d}$. $\mathrm{nm}$ decreased, which could be due to many surface charges present, contributing to the nanocomposite's hydrodynamic diameter. Earlier reports have suggested that silver nanoparticles synthesized using different molar ratios of silver with collagen resulted in a change in the hydrodynamic diameter due to the presence of different charge groups, resulting in a change in the potential difference [69].

Zeta potential values of silver nanoparticles and dendrimer bound to silver nanoparticles along with the change in the potential difference after encapsulation of dexamethasone and cross-linked to collagen were noted. The zeta potential of silver nanoparticles and dendrimer based nanocomposite is $-20.6 \mathrm{mV}$ for $\mathrm{AgNp}(\mathrm{A}) ; 3.63 \mathrm{mV}$ for AgNp@Den; -0.840 mV for AgNp@Den@Dex and -14.6 mV for AgNp@Den@Dex@Col. The potential zeta distribution of synthesized and fabricated nanoparticles is presented in Figure 4.

Figure. 4 provides information on the zeta potential distribution. To understand the colloidal solution's electrical traits upon binding and interactions, zeta potential measurements are used [70,71]. Citrate stabilized silver nanoparticles showed negative potential values of - 
$20 \mathrm{mV}$, which could be due to nanoparticles' higher surface energy after purification due to capped citric acid and electrostatic stabilization of the capping agent [72,73].

The binding of dendrimers with the nanoparticles determines nanoparticles' stability, which can be deciphered by the potential measurements [74]. The positive zeta potential could be due to the presence of amine groups in the dendrimer. This is also an indication that dendrimer is functionalized on top of silver nanoparticles. Values of $+3 \mathrm{mV}$ could be due to the aggregation of nanoparticles, while the broader UV-Vis spectrum can see functionalization of AgNp@Den compared to Den. The near-zero zeta measurement of drug entrapped AgNp@Den indicates drug entrapment, and a broader UV-Vis spectrum suggests aggregated nanoparticles. Collagen, a protein that contains different amino acids and is easily ionizable. The negative zeta potential of AgNp@Den@Dex@Col is a clear indication of the dendrimerbased nanomaterial on the collagen matrix. The reduction in the $\mathrm{d}$. $\mathrm{nm}$ is in good correlation with the increase in the zeta potential values of $-14 \mathrm{mV}$.
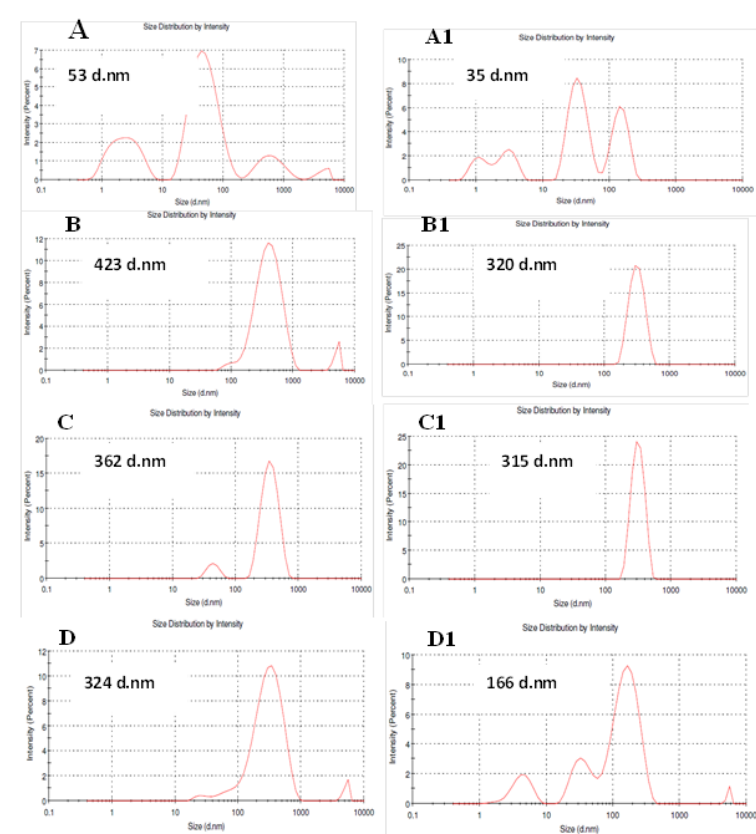

Figure. 3. Hydrodynamic diameter of synthesized and fabricated nanoparticles before and after centrifugation A/A1 - AgNp, B/B1 - AgNp@Den, $\mathrm{C} / \mathrm{C} 1$ - AgNP@Den@Dex and AgNp@Den@Dex@Col

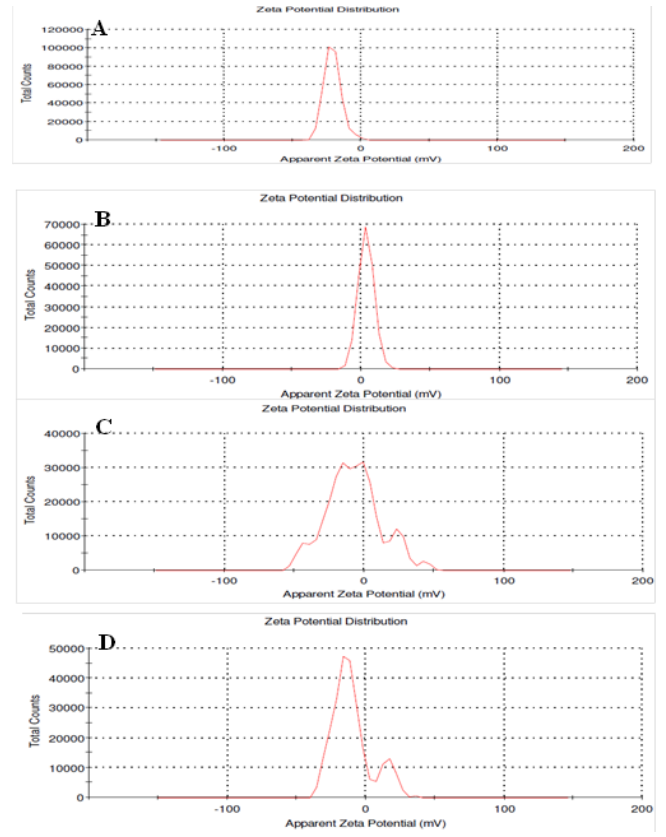

Figure. 4. Fig. 4. Zeta potential distribution of synthesized and fabricated nanoparticles A) $\mathrm{AgNp}$, B) AgNp@Den, C) AgNP@Den@Dex and D) AgNp@Den@Dex@Col

Figure 5 provides information on the micrographs of dendrimer functionalized silver nanoparticles and cross-linked collagen bound to dendrimer with functionalities. TEM studies were carried out to understand the morphological changes and the changes upon interaction with collagen. The localized surface plasmon resonance band shift is evident from UV-Vis spectra. From TEM pictures, AgNP@Den@Dex@Col showed the web-like or mat-like formation of nanocomposites due to cross-linking with collagen.

The vibrational bands' changes upon the interaction between citric acid and silver nanoparticles - AgNp, Interaction between dendrimer and silver nanoparticle for - AgNp@Den, entrapment/adsorption of dexamethasone in dendrimer - AgNp@Den@Dex, and cross-linked collagen to fabricated nanoparticles - AgNp@Den@Dex@Col are presented in Figure 6. The vibrational states of molecules of collagen, as well as dendrimer, are also presented in Figure 6. 
Figure. 6 provides detailed information about the functional groups involved in the formation interaction of silver nanoparticles and interaction with dendrimer. The band assignments involved by the presence of citric acid, the involvement of $-\mathrm{NH}$ stretching in functionalization of silver nanoparticles, the involvement of carboxylic group and amide bands of dendrimer collagen is presented in Table 1. FTIR spectrum confirms binding, entrapment, functionalization, and cross-linking [75-77].
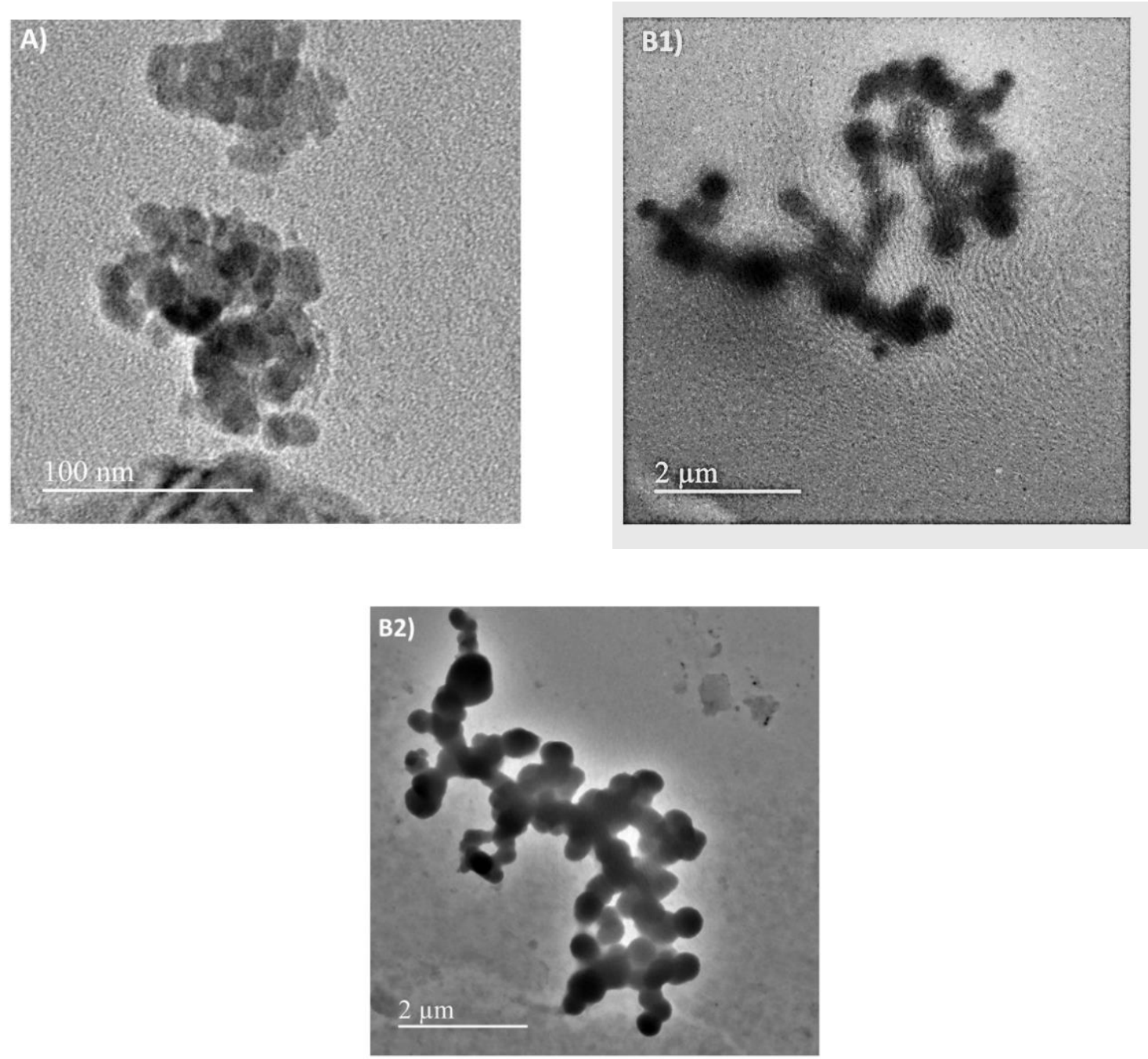

Figure 5. TEM micrographs of (A)AgNp@Den@Dex; (B1 and B2)AgNp@Den@Dex@Col.

Thermal degradation of collagen and collagen cross-linked with nanocomposites is presented in Figure 7. There was a $90 \%$ degradation of collagen at $49{ }^{\circ} \mathrm{C}$, as observed from the figure. For cross-linked collagen, the degradation can be seen at $52{ }^{\circ} \mathrm{C}$ where only $86 \%$ degradation has taken place.

The pattern of decomposition of collagen is presented in Figure 7. The stability of collagen can be improved by cross-linking, and TGA results can suggest whether there is any improvement to collagen decomposition temperature. From the figure, it can be understood that cross-linked collagen is more stable than native collagen. Earlier reports have also suggested that binding collagen to nanoparticles can improve the stability of collagen. Our results are in good correlation with the previous reports [78]. 


\subsection{Antibacterial activity: zone of inhibition.}

Figure 8a provides information on the zone of inhibition of Klebsiella pneumoniae: by AgNP@Dex@Den@Col. The minimum inhibitory concentration was found by varying the amount of AgNP from $5 \mu \mathrm{g}$ to $35 \mu \mathrm{g} / \mathrm{mL}$ and the same was found to be $25 \mu \mathrm{g} / \mathrm{mL}$. Figure $8 \mathrm{a}$ (D) shows the zone of inhibition of AgNP (1), Den (2), AgNP@Den (3), AgNP@Den@Dex@Col (4) and AgNP@Dex@Den (5). The zone of inhibition of AgNP@Den@Dex@Col was found to be 9 mm as against 1, 2.5, 3.0, 4.0 mm, respectively, for other systems investigated. It can be seen that the minimum inhibitory concentration for AgNP@Den@Dex@Col was $25 \mu \mathrm{g} / \mathrm{mL}$, and the zone of inhibition was 3.5 mm (Figure 8a).

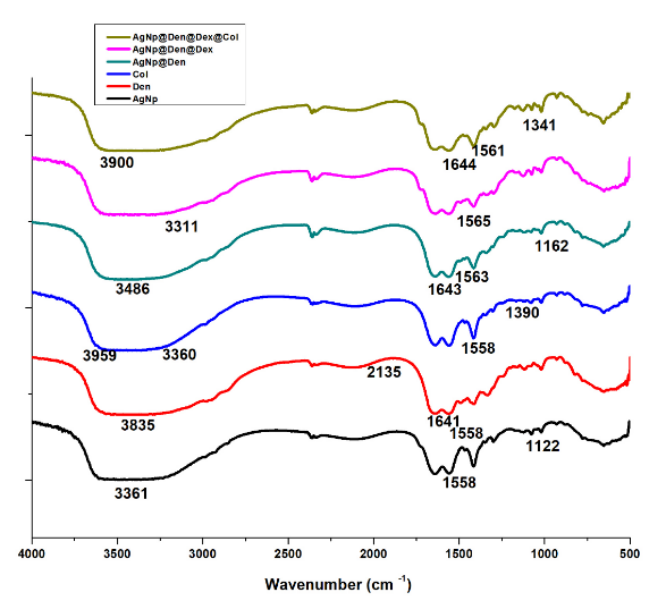

Figure 6. FT IR images of synthesized and fabricated nanoparticles (A) AgNp; (B) Den; (C) Col; (D) AgNp@Den; (E) AgNP@Den@Dex; (F) AgNp@Den@Dex@Col.

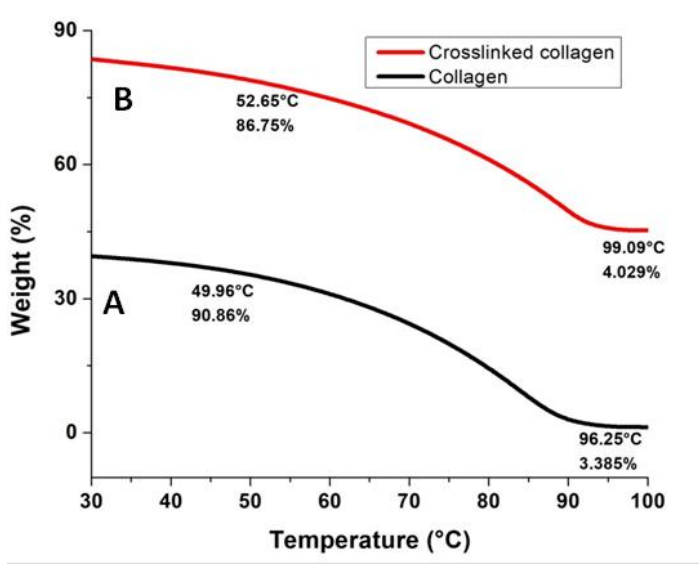

Figure 7. TGA analysis of (A) collagen alone; $(\mathbf{B})$ AgNp@Den@Dex@Col.

Figure 8b provides information on the zone of inhibition of Staphylococcus aureus by AgNP@Dex@Den@Col. The minimum inhibitory concentration was found by varying the amount of AgNP from $5 \mu \mathrm{g}$ to $35 \mu \mathrm{g} / \mathrm{mL}$ and the same was found to be $25 \mu \mathrm{g} / \mathrm{mL}$. Figure. $8 \mathrm{~b}$ (D) shows the zone of inhibition of AgNP (1), Den (2), AgNP@Den (3), AgNP@Den@Dex@Col (4) and AgNP@Dex@Den (5). The zone of inhibition of AgNP@Den@Dex@Col was found to be 15 mm as against 10, 11, 11.5, 12 mm, respectively, for other systems investigated. It can be seen that the minimum inhibitory concentration for AgNP@Den@Dex@Col was $25 \mu \mathrm{g} / \mathrm{mL}$, and the zone of inhibition was 5.0 mm (Figure 8b).

Table 1. FT-IR band assignments of synthesized and fabricated nanoparticles.

\begin{tabular}{l|l}
\multicolumn{1}{c|}{ Sample } & Band Assignment and Wavenumber $\left(\mathbf{c m}^{-1}\right)$ \\
\hline AgNp & $\begin{array}{l}\text { O-H and N-H stretching (3361), Asymmetric stretching of a carboxylic group (1558), } \\
\text { Stretching vibration of C-O-C (1122) }\end{array}$ \\
\hline Den & O-H (3835), O-H or N-H (1641), C-C(2135), stretching of a carboxylic group (1558) \\
\hline Col & $\begin{array}{l}\text { Amide A and B bands stretching vibration of N-H (3959), (3360), Amide II N-H } \\
\text { bending and C-H stretching (1643), Stretching vibration of C-O group (1558), Amide } \\
\text { III N-H bending and C-N stretching (1390) }\end{array}$ \\
\hline AgNp@Den & $\begin{array}{l}\text { Shift in O-H and N-H stretching (3486), Carboxylic group (1563), N-H (1643), } \\
\text { stretching vibration C-O-C (1162) }\end{array}$ \\
\hline AgNp@Den@Dex & $\begin{array}{l}\text { O-H and N-H (3311), Stretching of a carboxylic group (1565), changes in vibration at } \\
\text { 900 to 1600 due to dexamethasone incorporation. }\end{array}$ \\
\hline AgNp@Den@Dex@Col & $\begin{array}{l}\text { Stretching vibration O-H (3900), Stretching vibration N-H (1644), Amide III : N-H } \\
\text { bending (1341), Stretching vibration of Carboxylic group (1561) }\end{array}$
\end{tabular}




\subsection{Antibacterial activity: bacterial growth inhibition.}

Figure. 9 shows the growth inhibition of Staphylococcus aureus (a) and Klebsiella pneumoniae (b). Figure $9 \mathrm{a}$ and $9 \mathrm{~b}$ shows that 50 ( $\mathrm{L}$ of the sample when added with the microorganism indicated a significant inhibition in the growth of the microorganism $(\mathrm{P}<0.05)$ compared to control. The fabricated nanocomposites AgNP@Den@Dex@Col showed maximum inhibition compared to other groups, and growth inhibition was $71 \%$ for Staphylococcus aureus (a) and $45 \%$ for Klebsiella pneumoniae (b).

(a)
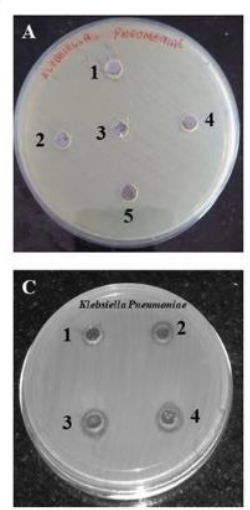
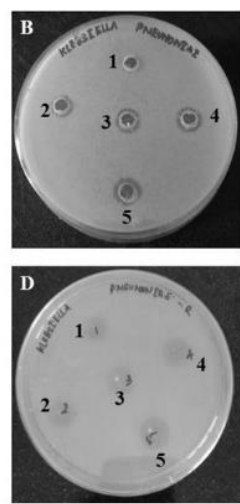

(b)
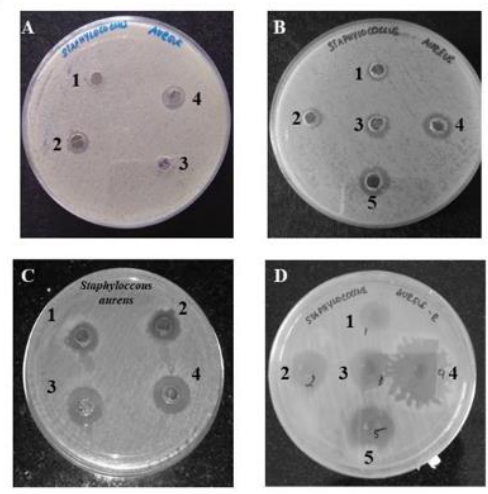

Figure. 8. (a) Zone of inhibition of Klebsiella pneumoniae: A: $2.5 \mu \mathrm{g} / \mathrm{mL}$ (1), $5.0 \mu \mathrm{g} / \mathrm{mL}$ (2), $7.5 \mu \mathrm{g} / \mathrm{mL}$ (3), $10.0 \mu \mathrm{g} / \mathrm{mL}$ (4), $12.5 \mu \mathrm{g} / \mathrm{mL}$ (5); B: $15.0 \mu \mathrm{g} / \mathrm{mL}$ (1), $17.5 \mu \mathrm{g} / \mathrm{mL}$ (2), $20.0 \mu \mathrm{g} / \mathrm{mL}$ (3), $22.5 \mu \mathrm{g} / \mathrm{mL}$ (4), 25.0 $\mu \mathrm{g} / \mathrm{mL}$ (5), C: $27.5 \mu \mathrm{g} / \mathrm{mL}$ (1), $30.0 \mu \mathrm{g} / \mathrm{mL}$ (2), $32.5 \mu \mathrm{g} / \mathrm{mL}$ (3), $35.0 \mu \mathrm{g} / \mathrm{mL}$ (4), D: AgNP (1), Den (2), AgNP@Den (3),AgNP@Den@Dex@Col (4),AgNP@Den@Dex (5)-50 $\mu \mathrm{L}$ of synthesized samples were added to these samples. (b) Zone of inhibition of Staphylococcus aureus a: $2.5 \mu \mathrm{g} / \mathrm{mL}$ (1), $5.0 \mu \mathrm{g} / \mathrm{mL}$ (2), 7.5 $\mu \mathrm{g} / \mathrm{mL}$ (3), $10.0 \mu \mathrm{g} / \mathrm{mL}$ (4), $12.5 \mu \mathrm{g} / \mathrm{mL}$ (5); b:15.0 $\mu \mathrm{g} / \mathrm{mL}$ (1), $17.5 \mu \mathrm{g} / \mathrm{mL}$ (2), $20.0 \mu \mathrm{g} / \mathrm{mL}$ (3), $22.5 \mu \mathrm{g} / \mathrm{mL}$ (4), $25.0 \mu \mathrm{g} / \mathrm{mL}$ (5), c: $27.5 \mu \mathrm{g} / \mathrm{mL}$ (1), $30.0 \mu \mathrm{g} / \mathrm{mL}$ (2), $32.5 \mu \mathrm{g} / \mathrm{mL}$ (3), $35.0 \mu \mathrm{g} / \mathrm{mL}$ (4), d: AgNP (1), Den (2),AgNP@Den (3),AgNP@Den@Dex@Col (4),AgNP@Den@Dex (5) - $50 \mu \mathrm{L}$ of synthesized samples were added to these samples.

(a)

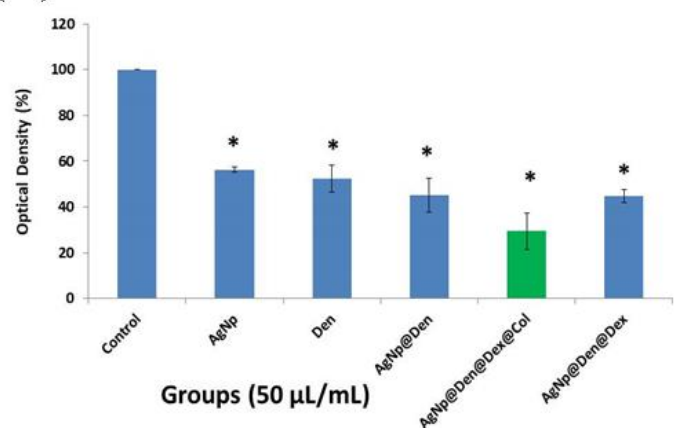

(b)

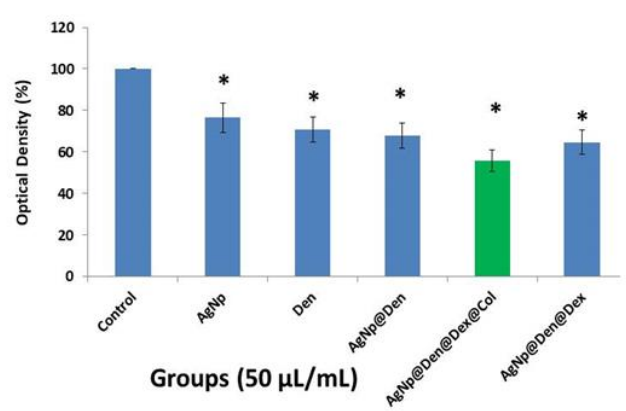

Figure. 9. Growth inhibition of (a) Staphylococcus aureus; (b) Klebsiella pneumoniae by $50 \mu \mathrm{L}$ of AgNP, Den,AgNP@Den,AgNP@Den@Dex@Col and AgNP@Den@Dex.

\subsection{Antibiofilm activity: Crystal Violet and Safranin O staining assay.}

The antibiofilm activity was carried out against gram-positive and gram-negative by crystal violet safranin staining for Staphylococcus aureus and Klebsiella pneumoniae. Biofilm was allowed to form $24 \mathrm{~h}$ after biofilm formation, $50 \mu \mathrm{L}$ of AgNP, Den, AgNP@Den, AgNP@Den@Dex@Col, and AgNP@Den@Dex was added to the biofilm and kept for 24 h. 
Figure 10a and Figure 10b show that there was very little biofilm formation (E) when AgNP@Den@Dex@Col was added compared to other groups. The percentage of inhibition is depicted in Figure 10a and Figure 10b; there was a $60 \%$ reduction in biofilm formation against Staphylococcus aureus and $40 \%$ against Klebsiella pneumoniae by the fabricated nanocompositeAgNP@Den@Dex@Col.

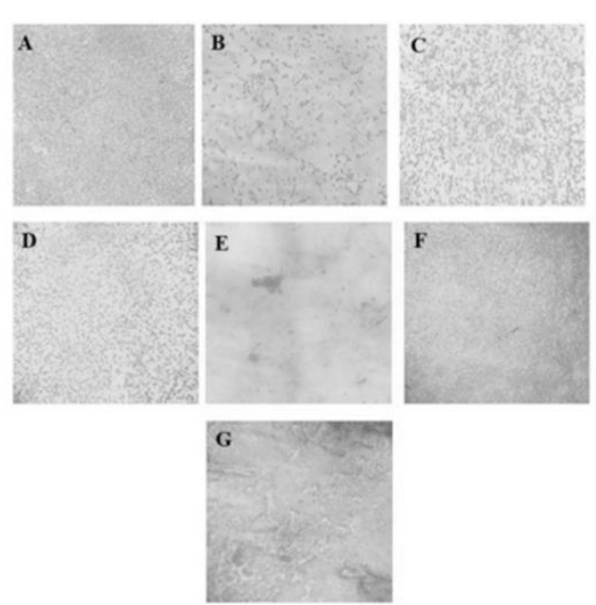

(a)
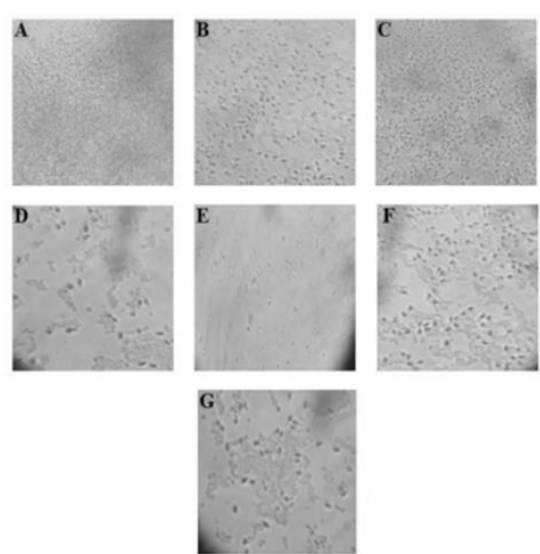

(b)

Figure 10. (a) Anti-biofilm activity by safranin O staining against Klebsiella pneumoniae: A) Control, B) AgNP, C)AgNP@Den, D) AgNP@Den@Dex, E)AgNP@Den@Dex@Col, F) Den, G) Col. (b) Antibiofilm activity by crystal violet staining against Staphylococcus aureus: A) Control, B) AgNP, C) AgNP@Den, D) AgNP@Den@Dex, E) AgNP@Den@Dex@Col, F) Den, G) Col.

To understand the inhibitory effect of AgNP@Den@Dex@Col, HRSEM analysis was carried out. Briefly, the bacteria Staphylococcus aureus was grown on a coverslip. Another coverslip AgNP@Den@Dex@Col was coated, and the bacteria (Staphylococcus aureus and Klebsiella pneumoniae) were allowed to grow for $24 \mathrm{~h}$. The coverslips were fixed and analyzed using HRSEM, and from Figure $11 \mathrm{~A}$ and $\mathrm{B}$, it can be seen that the fabricated nanofilm inhibited the formation of biofilm. The inhibitory effect of AgNP@Den@Dex@Col can be understood by the disruption of the integrity of bacterial surfaces. Earlier reports a similar biocidal activity of nanoparticles towards bacteria after $6 \mathrm{~h}$ of incubation with nanoparticles [79].

Figures $11 \mathrm{C}$ and D provide a detailed description of the anti-biofilm, inhibition of growth formation, and prevention of biofilm formation by AgNp, Den, AgNp@Den, AgNp@Den@Dex@Col, and AgNp@Den@Dex. From all the groups, it can be seen that AgNp@Den@Dex@Col prevented the formation or inhibition or reduction better than the other groups. For the two organisms tested, the nanocomposite activity was better against Staphylococcus aureus compared to Klebsiella pneumoniae.

It is interesting to note that Streptococcus mutans is the main reason for cause of dental caries [80]. In this study, the effect of AgNp@Den@Dex@Col is more against gram-positive than against gram-negative.

Zeta potential measurements in this study revealed that the charge on the matrix's surface is mainly negative. Earlier reports have suggested nanoparticles with a negative charge are more potent antibacterial agents [81]. Earlier reports have indicated the use of nanoparticles as a good biofilm degradative material $[79,82]$, and hence, incorporation of dexamethasone can pave the way to regenerative potential of the nanocomposite. 

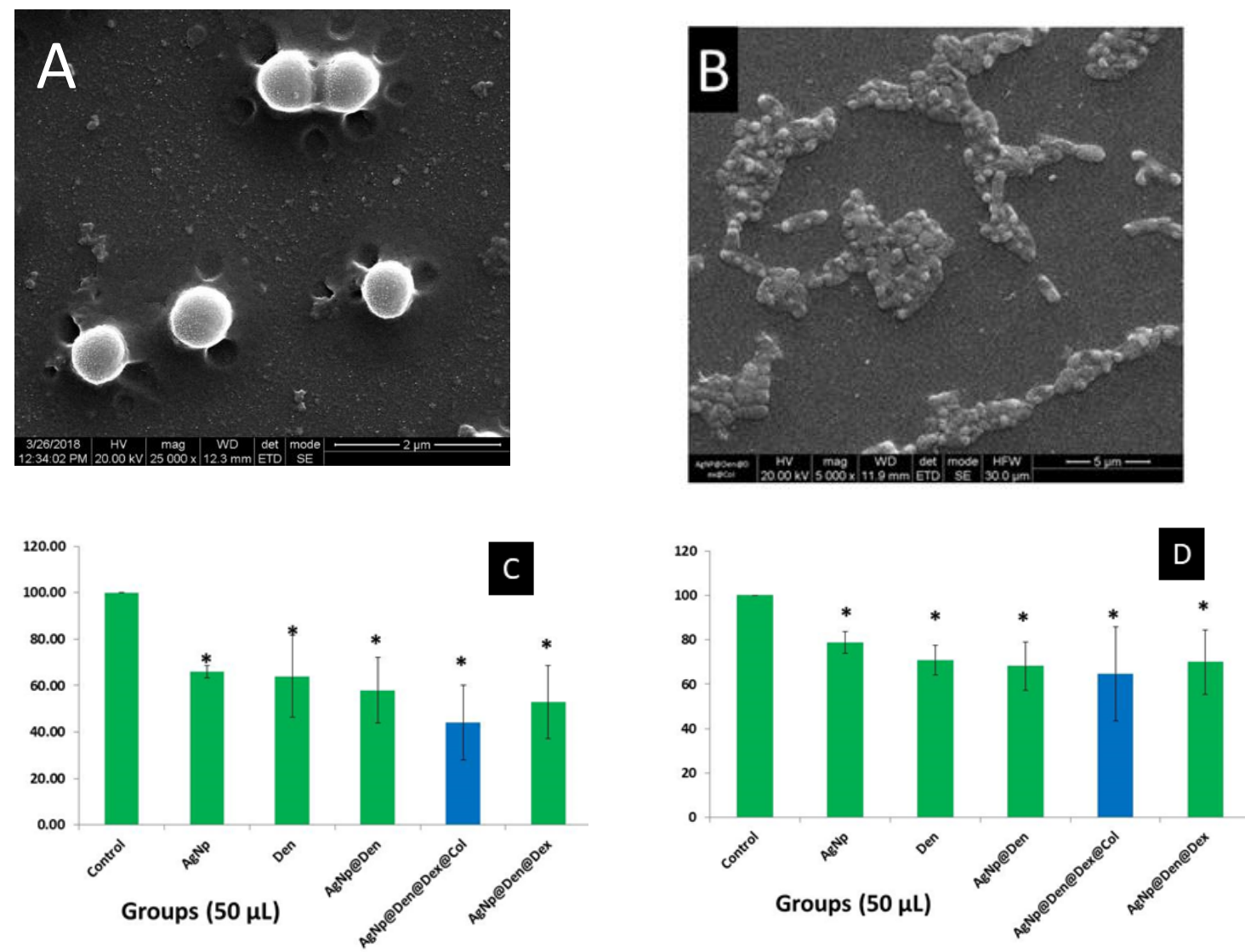

Figure 11. HR-SEM images of Staphylococcus aureus (A) Klebsiella pneumoniae (B) treated with AgNP@Den@Dex@Col and Percentage of biofilm formation; Staphylococcus aureus (C); Klebsiella pneumoniae (D).

\section{Conclusions}

The salient outputs from this work are PAMAM dendrimer's functionalization to silver nanoparticles to protect the nanoparticles from aggregating and reducing its cytotoxicity without affecting the antibacterial properties. The concept has been demonstrated successfully in this work as the AgNP@Den@Dex@Col showed 71\% for Staphylococcus aureus and reduced biofilm formation against Staphylococcus aureus by $60 \%$ and against Klebsiella pneumoniae by $40 \%$. Entrapping dexamethasone into the dendrimer's cavities was done to ensure a slow release of the drug that is vital for the dental pulp stem cell differentiation to odontoblasts. It was demonstrated by way of increased particle size and functional groups' presence and enhancing collagen's functional properties. By cross-linking collagen to dendrimer through EDC, collagen's stability was found to increase with a denaturation temperature of $52^{\circ} \mathrm{C}$ as measured by TGA.

\section{Funding}

This research received no external funding. This research was funded by the Chettinad Academy of Research and Education as part of a postgraduate project. 


\section{Acknowledgments}

SP thanks LTMT for JRF. We thank IIT Madras for instrumentation facilities (HR-SEM and HR-TEM).

\section{Conflicts of Interest}

The authors declare no conflict of interest.

\section{References}

1. Smith, E.E.; Yelick, P.C. Progress in Bioengineered Whole Tooth Research: From Bench to Dental Patient Chair. Current oral health reports 2016, 3, 302-308, https://doi.org/10.1007/s40496-016-0110-2.

2. Sun, H.H.; Jin, T.; Yu, Q.; Chen, F.M. Biological approaches toward dental pulp regeneration by tissue engineering. J. Tissue Eng. Regen. Med. 2011, 5, E1-E16, https://doi.org/10.1002/term.369.

3. Miura, M.; Gronthos, S.; Zhao, M.; Lu, B.; Fisher, L.W.; Robey, P.G.; Shi, S. SHED: stem cells from human exfoliated deciduous teeth. Proceedings of the National Academy of Sciences of the United States of America 2003, 100, 5807-5812, https://doi.org/10.1073/pnas.0937635100.

4. Park, Y.H.; Lee, Y.S.; Seo, Y.M.; Seo, H.; Park, J.S.; Bae, H.S.; Park, J.C. Midkine Promotes Odontoblastlike Differentiation and Tertiary Dentin Formation. J Dent Res 2020, 99, 1082-1091, https://doi.org/10.1177/0022034520925427.

5. Huang, G.T.; Shagramanova, K.; Chan, S.W. Formation of odontoblast-like cells from cultured human dental pulp cells on dentin in vitro. $J$ Endod 2006, 32, 1066-1073, https://doi.org/10.1016/j.joen.2006.05.009.

6. Cui, D.; Xiao, J.; Zhou, Y.; Zhou, X.; Liu, Y.; Peng, Y.; Yu, Y.; Li, H.; Zhou, X.; Yuan, Q., et al. Epiregulin enhances odontoblastic differentiation of dental pulp stem cells via activating MAPK signalling pathway. Cell Prolif 2019, 52, e12680, https://doi.org/10.1111/cpr.12680.

7. Zhang, M.; Ni, S.; Zhang, X.; Lu, J.; Gao, S.; Yang, Y.; Wang, Z.; Sun, H.; Li, Y. Dexamethasone-loaded hollow hydroxyapatite microsphere promotes odontogenic differentiation of human dental pulp cells in vitro. Odontology 2020, 108, 222-230, https://doi.org/10.1007/s10266-019-00459-x.

8. Shrestha, S.; Diogenes, A.; Kishen, A. Temporal-controlled Dexamethasone Releasing Chitosan Nanoparticle System Enhances Odontogenic Differentiation of Stem Cells from Apical Papilla. Journal of endodontics 2015, 41, 1253-1258, https://doi.org/10.1016/j.joen.2015.03.024.

9. Oliveira, J.M.; Kotobuki, N.; Tadokoro, M.; Hirose, M.; Mano, J.F.; Reis, R.L.; Ohgushi, H. Ex vivo culturing of stromal cells with dexamethasone-loaded carboxymethylchitosan/poly(amidoamine) dendrimer nanoparticles promotes ectopic bone formation. Bone 2010, 46, 1424-1435, https://doi.org/10.1016/j.bone.2010.02.007.

10. Moonesi Rad, R.; Atila, D.; Akgün, E.E.; Evis, Z.; Keskin, D.; Tezcaner, A. Evaluation of human dental pulp stem cells behavior on a novel nanobiocomposite scaffold prepared for regenerative endodontics. Materials Science and Engineering: C 2019, 100, 928-948, https://doi.org/10.1016/j.msec.2019.03.022.

11. Duailibi, S.E.; Duailibi, M.T.; Zhang, W.; Asrican, R.; Vacanti, J.P.; Yelick, P.C. Bioengineered dental tissues grown in the rat jaw. J Dent Res 2008, 87, 745-750, https://doi.org/10.1177/154405910808700811.

12. Ciocilteu, M.-V.; Filip, O.-L.; Valentin, C.; Manda, O.-E.N.; Neacșu, I.A.; Ficai, A.; Buzatu, I.-M.; Nicolicescu, C.; Croitoru, O.; Neamţu, J. Physico-Chemical Characterization And Antibacterial Activity Of A Controlled Collagen-Hydroxyapatite-Ciprofloxacin Release System. Farmacia 2020, 68, 1055-1061, https://doi.org/10.31925/farmacia.2020.6.12.

13. Neacsu, I.A.; Serban, A.P.; Nicoara, A.I.; Trusca, R.; Ene, V.L.; Iordache, F. Biomimetic Composite Scaffold Based on Naturally Derived Biomaterials. Polymers 2020, 12, 1161, https://doi.org/10.3390/polym12051161.14. Neacsu, I.A.; Arsenie, L.V.; Trusca, R.; Ardelean, I.L.; Mihailescu, N.; Mihailescu, I.N.; Ristoscu, C.; Bleotu, C.; Ficai, A.; Andronescu, E. Biomimetic Collagen/Zn(2+)-Substituted Calcium Phosphate Composite Coatings on Titanium Substrates as Prospective Bioactive Layer for Implants: A Comparative Study Spin Coating vs. MAPLE. Nanomaterials (Basel) 2019, 9, 692, https://doi.org/10.3390/nano9050692.

15. Tan, H.P.; Marra, K.G. Injectable, Biodegradable Hydrogels for Tissue Engineering Applications. Materials 2010, 3, 1746-1767, https://doi.org/10.3390/ma3031746. 
16. Barth, A. Infrared spectroscopy of proteins. Biochim. Biophys. Acta-Bioenerg. 2007, 1767, 1073-1101. https://doi.org/10.1016/j.bbabio.2007.06.004.

17. Ryglova, S.; Braun, M.; Suchy, T. Collagen and Its Modifications-Crucial Aspects with Concern to Its Processing and Analysis. Macromol. Mater. Eng. 2017, 302, 29, https://doi.org/10.1002/mame.201600460.

18. Daamen, W.F.; van Moerkerk, H.T.B.; Hafmans, T.; Buttafoco, L.; Poot, A.A.; Veerkamp, J.H.; van Kuppevelt, T.H. Preparation and evaluation of molecularly-defined collagen-elastin-glycosaminoglycan scaffolds for tissue engineering. Biomaterials 2003, 24, 4001-4009, https://doi.org/10.1016/s01429612(03)00273-4.

19. Kubies, D.; Himmlova, L.; Riedel, T.; Chanova, E.; Balik, K.; Douderova, M.; Bartova, J.; Pesakova, V. The Interaction of Osteoblasts With Bone-Implant Materials: 1. The Effect of Physicochemical Surface Properties of Implant Materials. Physiol. Res. 2011, 60, 95-111, https://doi.org/10.33549/physiolres.931882.

20. Fathima, N.N.; Dhathathreyan, A. Effect of surfactants on the thermal, conformational and rheological properties of collagen. Int. J. Biol. Macromol. 2009, 45, 274-278, https://doi.org/10.1016/j.ijbiomac.2009.06.003.

21. Kandamchira, A.; Selvam, S.; Marimuthu, N.; Sreeram, K.J.; Fathima, N.N. Influence of functionalized nanoparticles on conformational stability of type I collagen for possible biomedical applications. Materials Science \& Engineering C-Materials for Biological Applications 2013, 33, 4985-4988, https://doi.org/10.1016/j.msec.2013.08.018.

22. Sindhu, K.; Rajaram, A.; Sreeram, K.J.; Rajaram, R. Curcumin conjugated gold nanoparticle synthesis and its biocompatibility. Rsc Advances 2014, 4, 1808-1818, https://doi.org/10.1039/c3ra45345f.

23. Vedhanayagam, M.; Mohan, R.; Nair, B.U.; Sreeram, K.J. Nanorod mediated collagen scaffolds as extra cellular matrix mimics. Biomedical Materials 2015, 10, https://doi.org/10.1088/1748-6041/10/6/065010.

24. Vedhanayagam, M.; Nidhin, M.; Duraipandy, N.; Naresh, N.D.; Jaganathan, G.; Ranganathan, M.; Kiran, M.S.; Narayan, S.; Nair, B.U.; Sreeram, K.J. Role of nanoparticle size in self-assemble processes of collagen for tissue engineering application. Int. J. Biol. Macromol. 2017, 99, 655-664, https://doi.org/10.1016/j.ijbiomac.2017.02.102.

25. Svenson, S.; Tomalia, D.A. Commentary - Dendrimers in biomedical applications - reflections on the field. Adv. Drug Deliv. Rev. 2005, 57, 2106-2129, https://doi.org/10.1016/j.addr.2005.09.018.

26. Jaymand, M.; Lotfi, M.; Lotfi, R. Functional dendritic compounds: potential prospective candidates for dental restorative materials and in situ re-mineralization of human tooth enamel. Rsc Advances 2016, 6, 4312743146, https://doi.org/10.1039/c6ra05722e.

27. Wu, D.; Yang, J.J.; Li, J.Y.; Chen, L.; Tang, B.; Chen, X.Y.; Wu, W.; Li, J.S. Hydroxyapatite-anchored dendrimer for in situ re-mineralization of human tooth enamel. Biomaterials 2013, 34, 5036-5047, https://doi.org/10.1016/j.biomaterials.2013.03.053.

28. Gardiner, J.; Freeman, S.; Leach, M.; Green, A.; Alcock, J.; D'Emanuele, A. PAMAM dendrimers for the delivery of the antibacterial Triclosan. J. Enzym. Inhib. Med. Chem. 2008, 23, 623-628, https://doi.org/10.1080/14756360802205257.

29. Sharan, J.; Singh, S.; Lale, S.V.; Mishra, M.; Koul, V.; Kharbanda, O.P. Applications of Nanomaterials in Dental Science: A Review. J Nanosci Nanotechnol 2017, 17, 2235-2255, https://doi.org/10.1166/jnn.2017.13885.

30. Fernandes, T.; Bhavsar, C.; Sawarkar, S.; D'Souza, A. Current and novel approaches for control of dental biofilm. Int. J. Pharm. 2018, 536, 199-210, https://doi.org/10.1016/j.ijpharm.2017.11.019.

31. Palle, S.R.; Penchalaneni, J.; Lavudi, K.; Gaddam, S.A.; Kotakadi, V.S.; Challagundala, V.N. Green synthesis of silver nanoparticles by leaf extracts of boerhavia erecta and spectral characterization and their antimicrobial, antioxidant ad cytotoxic studies on ovarian cancer cell lines. Letters in Applied Nano Bio Science 2020, 9, 1165-1176, https://doi.org/10.33263/LIANBS93.11651176.

32. Sánchez-López, E.; Gomes, D.; Esteruelas, G.; Bonilla, L.; Lopez-Machado, A.L.; Galindo, R.; Cano, A.; Espina, M.; Ettcheto, M.; Camins, A., et al. Metal-Based Nanoparticles as Antimicrobial Agents: An Overview. Nanomaterials 2020, 10, 292, https://doi.org/10.3390/nano10020292.

33. Tjandra, K.C.; Thordarson, P. Multivalency in Drug Delivery-When Is It Too Much of a Good Thing? Bioconjug Chem. 2019, 30, 503-514, https://doi.org/10.1021/acs.bioconjchem.8b00804.

34. Bangarakodi, K.; Rajamanickam, D.; Jeyaraman, A.; Srinivasan, B. Preparation and Characterization of Wound Dressings Incorporated with Curcumin, Povidone Iodine, and Silver Sulphadiazine. Letters in Applied Nano Bio Science 2020, 10, 1748 - 1759, https://doi.org/10.33263/LIANBS101.17481759.

35. Peulen, T.O.; Wilkinson, K.J. Diffusion of Nanoparticles in a Biofilm. Environ. Sci. Technol. 2011, 45, 33673373, https://doi.org/10.1021/es103450g. 
36. Vasile, O.R.; Andronescu, E.; Truşcă, R.; Vasile, E.; Holban, A.M.; Chifiriuc, M.C.; Iordache, F.; Maniu, H.; Bleotu, C.; Neacşu, I.A., et al. Structure-grain size-synthesis route of silver nanoparticles: a correlation with the cytotoxic effect. Romanian journal of morphology and embryology = Revue roumaine de morphologie et embryologie 2019, 60, 617-628.

37. Sanyasi, S.; Majhi, R.K.; Kumar, S.; Mishra, M.; Ghosh, A.; Suar, M.; Satyam, P.V.; Mohapatra, H.; Goswami, C.; Goswami, L. Polysaccharide-capped silver Nanoparticles inhibit biofilm formation and eliminate multi-drug-resistant bacteria by disrupting bacterial cytoskeleton with reduced cytotoxicity towards mammalian cells. Scientific Reports 2016, 6, 24929, https://doi.org/10.1038/srep24929.

38. Paula, A.J.; Koo, H. Nanosized Building Blocks for Customizing Novel Antibiofilm Approaches. Journal of dental research 2017, 96, 128-136, https://doi.org/10.1177/0022034516679397.

39. Crooks, R.M.; Zhao, M.Q.; Sun, L.; Chechik, V.; Yeung, L.K. Dendrimer-encapsulated metal nanoparticles: Synthesis, characterization, and applications to catalysis. Acc Chem Res 2001, 34, 181-190, https://doi.org/10.1021/ar000110a.

40. Quintero-Quiroz, C.; Acevedo, N.; Zapata-Giraldo, J.; Botero, L.E.; Quintero, J.; Zárate-Triviño, D.; Saldarriaga, J.; Pérez, V.Z. Optimization of silver nanoparticle synthesis by chemical reduction and evaluation of its antimicrobial and toxic activity. Biomater Res 2019, 23, 27, https://doi.org/10.1186/s40824019-0173-y.

41. Ning, D.; Zhang, H.; Zheng, J. Electrochemical sensor for sensitive determination of nitrite based on the PAMAM dendrimer-stabilized silver nanoparticles. Journal of Electroanalytical Chemistry 2014, 717-718, 29-33, https://doi.org/10.1016/j.jelechem.2013.12.011.

42. Lim, H.-C.; Nam, O.H.; Kim, M.-j.; El-Fiqi, A.; Yun, H.-M.; Lee, Y.-M.; Jin, G.-Z.; Lee, H.-H.; Kim, H.W.; Kim, E.-C. Delivery of dexamethasone from bioactive nanofiber matrices stimulates odontogenesis of human dental pulp cells through integrin/BMP/mTOR signaling pathways. International Journal of Nanomedicine 2016, 11, 2557-2567, https://doi.org/10.2147/IJN.S97846.

43. Lee, A.S.; Inayathullah, M.; Lijkwan, M.A.; Zhao, X.; Sun, W.; Park, S.; Hong, W.X.; Parekh, M.B.; Malkovskiy, A.V.; Lau, E., et al. Prolonged survival of transplanted stem cells after ischaemic injury via the slow release of pro-survival peptides from a collagen matrix. Nature Biomedical Engineering 2018, 2, 104113, https://doi.org/10.1038/s41551-018-0191-4.

44. Liu, T.; Song, X.; Guo, Z.; Dong, Y.; Guo, N.; Chang, X. Prolonged antibacterial effect of silver nanocomposites with different structures. Colloids and Surfaces B: Biointerfaces 2014, 116, 793-796, https://doi.org/10.1016/j.colsurfb.2014.01.010.

45. Mahapatra, S.S.; Karak, N. Silver nanoparticle in hyperbranched polyamine: Synthesis, characterization and antibacterial activity. Materials Chemistry and Physics 2008, 112, 1114-1119, https://doi.org/10.1016/j.matchemphys.2008.07.047.

46. Javan bakht Dalir, S.; Djahaniani, H.; Nabati, F.; Hekmati, M. Characterization and the evaluation of antimicrobial activities of silver nanoparticles biosynthesized from Carya illinoinensis leaf extract. Heliyon 2020, 6, e03624, https://doi.org/10.1016/j.heliyon.2020.e03624.

47. Khan, S.; Alam, F.; Azam, A.; Khan, A.U. Gold nanoparticles enhance methylene blue-induced photodynamic therapy: a novel therapeutic approach to inhibit Candida albicans biofilm. Int J Nanomedicine 2012, 7, 3245-3257, https://doi.org/10.2147/IJN.S31219.

48. Moreau, J.L.; Sun, L.; Chow, L.C.; Xu, H.H. Mechanical and acid neutralizing properties and bacteria inhibition of amorphous calcium phosphate dental nanocomposite. J Biomed Mater Res. Part B, App Biomater 2011, 98, 80-88, https://doi.org/10.1002/jbm.b.31834.

49. Noronha, V.T.; Paula, A.J.; Duran, G.; Galembeck, A.; Cogo-Muller, K.; Franz-Montan, M.; Duran, N. Silver nanoparticles in dentistry. Dental materials : official publication of the Academy of Dental Materials 2017, 33, 1110-1126, https://doi.org/10.1016/j.dental.2017.07.002.

50. Zhang, W.; Ke, S.; Sun, C.; Xu, X.; Chen, J.; Yao, L. Fate and toxicity of silver nanoparticles in freshwater from laboratory to realistic environments: a review. Environmental Science and Pollution Research 2019, 26, 7390-7404, https://doi.org/10.1007/s11356-019-04150-0.

51. Ferdous, Z.; Nemmar, A. Health Impact of Silver Nanoparticles: A Review of the Biodistribution and Toxicity Following Various Routes of Exposure. Int J Mol Sci 2020, 21, 2375. doi:10.3390/ijms21072375.

52. Stensberg, M.C.; Wei, Q.; McLamore, E.S.; Porterfield, D.M.; Wei, A.; Sepúlveda, M.S. Toxicological studies on silver nanoparticles: challenges and opportunities in assessment, monitoring and imaging. Nanomedicine (Lond.) 2011, 6, 879-898, https://doi.org/10.2217/nnm.11.78. 
53. Yadollahi, M.; Farhoudian, S.; Namazi, H. One-pot synthesis of antibacterial chitosan/silver bionanocomposite hydrogel beads as drug delivery systems. Int J Biol Macromol 2015, 79, 37-43, https://doi.org/10.1016/j.ijbiomac.2015.04.032.

54. Steinigeweg, D.; Schlucker, S. Monodispersity and size control in the synthesis of 20-100 nm quasi-spherical silver nanoparticles by citrate and ascorbic acid reduction in glycerol-water mixtures. Chem Comm 2012, 48, 8682-8684, https://doi.org/10.1039/c2cc33850e.

55. Saleh, T.A.; Al-Shalalfeh, M.M.; Al-Saadi, A.A. Graphene Dendrimer-stabilized silver nanoparticles for detection of methimazole using Surface-enhanced Raman scattering with computational assignment. Scientific Reports 2016, 6, 32185, https://doi.org/10.1038/srep32185.

56. Jiang, G.; Liu, S.; Yu, T.; Wu, R.; Ren, Y.; van der Mei, H.C.; Liu, J.; Busscher, H.J. PAMAM dendrimers with dual-conjugated vancomycin and Ag-nanoparticles do not induce bacterial resistance and kill vancomycin-resistant Staphylococci. Acta biomaterialia 2021, 123, 230-243, https://doi.org/10.1016/j.actbio.2021.01.032.

57. Madaan, K.; Kumar, S.; Poonia, N.; Lather, V.; Pandita, D. Dendrimers in drug delivery and targeting: Drugdendrimer interactions and toxicity issues. $J$ Pharm Bioallied Sci 2014, 6, 139-150, https://doi.org/10.4103/0975-7406.130965.

58. Calabretta, M.K.; Kumar, A.; McDermott, A.M.; Cai, C. Antibacterial Activities of Poly(amidoamine) Dendrimers Terminated with Amino and Poly(ethylene glycol) Groups. Biomacromolecules 2007, 8, 18071811, https://doi.org/10.1021/bm0701088.

59. Tang, J.; Chen, W.; Su, W.; Li, W.; Deng, J. Dendrimer-Encapsulated Silver Nanoparticles and Antibacterial Activity on Cotton Fabric. Journal of Nanoscience and Nanotechnology 2013, 13, 2128-2135, https://doi.org/10.1166/jnn.2013.6883.

60 Lee, J.-H.; Kang, M.-S.; Mahapatra, C.; Kim, H.-W. Effect of Aminated Mesoporous Bioactive Glass Nanoparticles on the Differentiation of Dental Pulp Stem Cells. PLoS ONE 2016, 11, e0150727. https://doi.org/10.1371/journal.pone.0150727.

61. Vyvey, M. Steroids as pain relief adjuvants. Can Fam Physician 2010, 56, 1295-1297.

62. Chang, M.C.; Tanaka, J. XPS study for the microstructure development of hydroxyapatite-collagen nanocomposites cross-linked using glutaraldehyde. Biomaterials 2002, 23, 3879-3885, https://doi.org/10.1016/s0142-9612(02)00133-3.

63. Zhong, S.; Yung, L.Y. Enhanced biological stability of collagen with incorporation of PAMAM dendrimer. J Biomed Mater Res A 2009, 91, 114-122, https://doi.org/10.1002/jbm.a.32188.

64. Beghetto, V.; Gatto, V.; Conca, S.; Bardella, N.; Scrivanti, A. Polyamidoamide Dendrimers and CrossLinking Agents for Stabilized Bioenzymatic Resistant Metal-Free Bovine Collagen. Molecules 2019, 24, 3611, https://doi.org/10.3390/molecules24193611.

65. Hannig, M.; Hannig, C. Nanomaterials in preventive dentistry. Nat Nanotechnol 2010, 5, 565, https://doi.org/10.1038/nnano.2010.83.

66. Holmes, D.F.; Graham, H.K.; Trotter, J.A.; Kadler, K.E. STEM/TEM studies of collagen fibril assembly. Micron 2001, 32, 273-285.

67. Busra, M.F.M.; Lokanathan, Y. Recent Development in the Fabrication of Collagen Scaffolds for Tissue Engineering Applications: A Review. Current pharmaceutical biotechnology 2019, 20, 992-1003. https://doi.org/10.2174/1389201020666190731121016.

68. Wei, S.M.; Pei, M.Y.; Pan, W.L.; Thissen, H.; Tsai, S.W. Gelatin Hydrogels Reinforced by Absorbable Nanoparticles and Fibrils Cured In Situ by Visible Light for Tissue Adhesive Applications. Polymers 2020, 12, https://doi.org/10.3390/polym12051113.

69. Cardoso, V.S.; Quelemes, P.V.; Amorin, A.; Primo, F.L.; Gobo, G.G.; Tedesco, A.C.; Mafud, A.C.; Mascarenhas, Y.P.; Corrêa, J.R.; Kuckelhaus, S.A.S., et al. Collagen-based silver nanoparticles for biological applications: synthesis and characterization. Journal of Nanobiotechnology 2014, 12, 36, https://doi.org/10.1186/s12951-014-0036-6.

70. Kuo, Y.-C.; Chen, I.C. Evaluation of Surface Charge Density and Surface Potential by Electrophoretic Mobility for Solid Lipid Nanoparticles and Human Brain-Microvascular Endothelial Cells. J Phys Chem B 2007, 111, 11228-11236, https://doi.org/10.1021/jp072876z.

71. Rasmussen, M.K.; Pedersen, J.N.; Marie, R. Size and surface charge characterization of nanoparticles with a salt gradient. Nature Communications 2020, 11, 2337, https://doi.org/10.1038/s41467-020-15889-3.

72. Agnihotri, S.; Mukherji, S.; Mukherji, S. Size-controlled silver nanoparticles synthesized over the range 5$100 \mathrm{~nm}$ using the same protocol and their antibacterial efficacy. RSC Advances 2014, 4, 3974-3983, https://doi.org/10.1039/C3RA44507K. 
73. Nkoh, J.N.; Lu, H.L.; Pan, X.Y.; Dong, G.; Kamran, M.A.; Xu, R.K. Effects of extracellular polymeric substances of Pseudomonas fluorescens, citrate, and oxalate on $\mathrm{Pb}$ sorption by an acidic Ultisol. Ecotoxicology and environmental safety 2019, 171, 790-797, https://doi.org/10.1016/j.ecoenv.2019.01.043.

74. Maiti, P.K.; Messina, R. Counterion Distribution and $\zeta$-Potential in PAMAM Dendrimer. Macromolecules 2008, 41, 5002-5006, https://doi.org/10.1021/ma7025435.

75. Li, R.S.; Liu, H.; Chen, B.B.; Zhang, H.Z.; Huang, C.Z.; Wang, J. Stable gold nanoparticles as a novel peroxidase mimic for colorimetric detection of cysteine. Analytical Methods 2016, 8, 2494-2501, https://doi.org/10.1039/C6AY00367B.

76. Qi, P.; Zhou, Y.; Wang, D.; He, Z.; Li, Z. A new collagen solution with high concentration and collagen native structure perfectly preserved. RSC Advances 2015, 5, 87180-87186, https://doi.org/10.1039/C5RA14423J.

77. Wang, Y.; Su, P.; Wang, S.; Wu, J.; Huang, J.; Yang, Y. Dendrimer modified magnetic nanoparticles for immobilized BSA: a novel chiral magnetic nano-selector for direct separation of racemates. Journal of Materials Chemistry B 2013, 1, 5028-5035, https://doi.org/10.1039/C3TB20889C.

78. Mandal, A.; Sekar, S.; Chandrasekaran, N.; Mukherjee, A.; Sastry, T.P. Synthesis, characterization and evaluation of collagen scaffolds cross-linked with aminosilane functionalized silver nanoparticles: in vitro and in vivo studies. Journal of Materials Chemistry B 2015, 3, 3032-3043, https://doi.org/10.1039/C4TB02124J.

79. Palaniraj, S.; Murugesan, R.; Narayan, S. Chlorogenic acid- loaded calcium phosphate chitosan nanogel as biofilm degradative materials. The International Journal of Biochemistry \& Cell Biology 2019, 114, 105566, https://doi.org/10.1016/j.biocel.2019.105566.

80. Melo, M.A.S.; Guedes, S.F.F.; Xu, H.H.K.; Rodrigues, L.K.A. Nanotechnology-based restorative materials for dental caries management. Trends in biotechnology 2013, 31, 10.1016/j.tibtech.2013.1005.1010, https://doi.org/10.1016/j.tibtech.2013.05.010.

81. Salvioni, L.; Galbiati, E.; Collico, V.; Alessio, G.; Avvakumova, S.; Corsi, F.; Tortora, P.; Prosperi, D.; Colombo, M. Negatively charged silver nanoparticles with potent antibacterial activity and reduced toxicity for pharmaceutical preparations. International journal of nanomedicine 2017, 12, 2517-2530. https://doi.org/10.2147/IJN.S127799.

82. Qiao, Z.; Yao, Y.; Song, S.; Yin, M.; Luo, J. Silver nanoparticles with pH induced surface charge switchable properties for antibacterial and antibiofilm applications. Journal of materials chemistry. B 2019, 7, 830-840. https://doi.org/10.1039/c8tb02917b. 